\title{
Transport of Moisture and Chlorides into Sprayed Concrete
}

\author{
Diego Aponte, Marilda Barra, Susanna Valls and Lucia Fernandez \\ Department of Civil and Environmental Engineering (DECA), Universitat Politècnica de Catalunya- \\ BarcelonaTECH, Campus Nord UPC, 08034-Barcelona, Spain, diego.fernando.aponte@upc.edu
}

\begin{abstract}
This contribution is a study of the durability and transport properties of sprayed concrete used in an actual construction site. It considers whether concrete spraying can generate different porosities as the thickness of the sprayed layer increases. The work consisted of a study of the properties of the interior and exterior concrete layers with a particular focus on chloride penetration. A few of the methodologies and techniques used are compressive strength at 28 days, depth of penetration of water under pressure UNE EN 12390-8, boiled absorption and volume of permeable voids ASTM C642, and accelerate chloride penetration NT BUILD 443. Calculated transport property values included absorption (A) and volume of permeable voids (VPV), porosity interconnection, and chloride diffusion coefficient (De). The conclusion obtained is that there are no significant differences between the physical microstructural properties of the interior and exterior sprayed concrete layers, they present a similar porosity, and behave in the same way under a chloride attack when test tubes are completely saturated.
\end{abstract}

Keywords: Sprayed Concrete, Moisture Movement, Chloride Penetration, Chloride Diffusion Coefficient, and Durability.

\section{Introduction}

Sprayed concrete is typically used in the construction and stabilization of tunnels, underground structures, and other construction sites where the application of traditional castin-place concrete is particularly challenging (Wang et al., 2015). Unlike conventional concrete, sprayed concrete has a short setting time as well as high mechanical properties due to the incorporation of set accelerating additives (Austin et al., 2002; Galobardes, 2013). At the same time, sprayed concrete presents more porosity than cast-in-place concrete, which can affect its durability by making it more vulnerable to damages caused by moisture, chemicals, and other external agents (Galobardes et al., 2014).

This study conducted a characterization of the physical, mechanic, and durability properties of sprayed concrete with two goals in mind. The first is to determine if, when studied by layers, sprayed concrete shows different transport properties depending on its proximity or direct contact with the projected surface. The second is to study the impact of the presence of chlorides introduced by moisture via the sprayed concrete's transport mechanisms to determine potential durability issues.

\section{Methodology}

This study was conducted with wet-mix sprayed concrete, using a CEM I 52.5 R, water/cement ratio 0,35 and $450 \mathrm{~kg} / \mathrm{m}^{3}$ of cement, a superplasticizer type 
MASTERCLENIUM SKY 554-BASF, and the accelerating additive MasterRoc SA 172 (which is non-alkaline and presents no alkalis or chlorides). Table 1 shows the dosage used in the shotcrete.

Table 1. Sprayed concrete dosage.

\begin{tabular}{ccc}
\hline Material & $\begin{array}{c}\text { Quantity } \\
\left(\mathrm{kg} / \mathrm{m}^{3}\right)\end{array}$ & $\begin{array}{c}\text { Quantity } \\
(\%)\end{array}$ \\
\hline Cement & 450 & 19.4 \\
\hline Water & 155 & 6.7 \\
\hline Sand 1 $(0 / 2 \mathrm{~mm})$ & 750 & 32.4 \\
\hline Sand 2 $(0 / 6 \mathrm{~mm})$ & 485 & 20.9 \\
\hline Medium Ag. $(4 / 12 \mathrm{~mm})$ & 435 & 18.8 \\
\hline Superplasticizer & 4.5 & 0.2 \\
\hline Accellerator & 38.2 & 1.7 \\
\hline
\end{tabular}

The wet mix concrete was sprayed on $4 \mathrm{~mm}$-thick metallic test panels located at an ongoing construction site, using $7-15 \mathrm{~m}^{3}$ air pressure per minute at a $90^{\circ}$ angle, and maintaining a $0.5-1.5 \mathrm{~m}$ distance to ensure all samples would be sprayed with similar speed, compaction, and adherence.

After the spraying, the mixes were transported to the Construction Materials Laboratory of the Universitat Politècnica de Catalunya, and they were left outdoors for 28 days to simulate

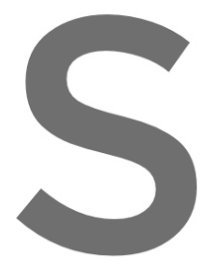
the environment to which they would have been initial 28 days, the nex from the test panels (Figr which are called parts $A$

Part $A$ is the first layer, which under real donditions
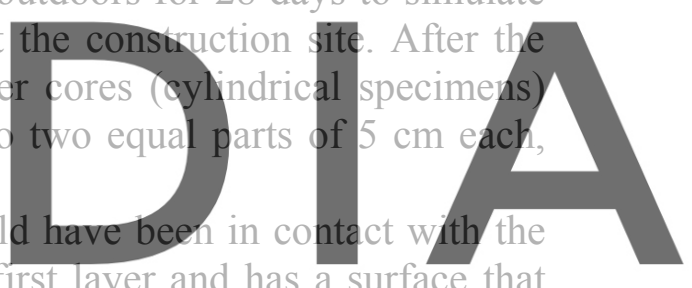
terrain. Part $\mathrm{R}$ is the second layer, which is adhered to the first layer and has a surface that was used to simulate exposure to open air. penetration, suction test and compressive strength. Two specimens of each type of sample are used for chloride penetration test.
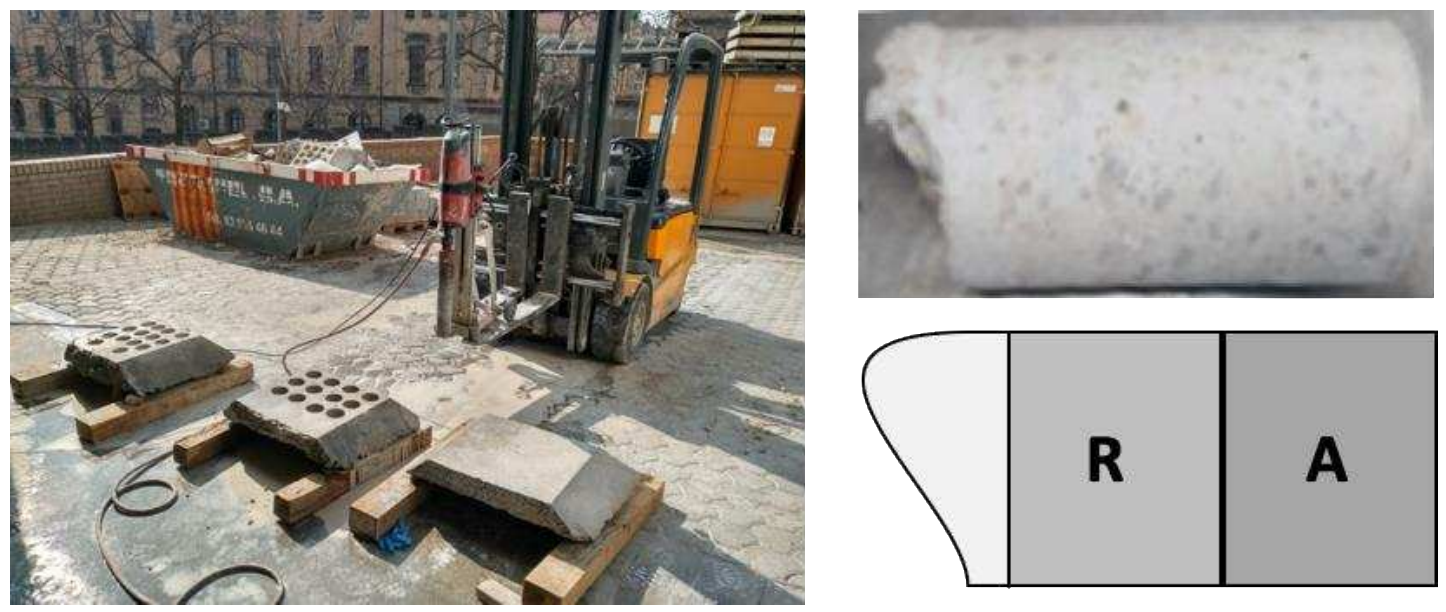

Figure 1. Extraction of sprayed concrete specimens (a) and division of samples into part A and part B. 


\subsection{Density, Absorption, and Porosity}

These specimens did not undergo any special preparations to test for density, absorption, or porosity. The test was conducted following the standard ASTM C642.

\subsection{Moisture Penetration under Pressure}

Epoxy paint was used to cover the lateral parts of the specimens, leaving only the two opposite faces of the cylinder exposed to ensure that the moisture flow would be vertical and ascending without lateral losses. This test used pressurized water under the surface of the hardened sprayed concrete for 72 hours, applying a $500 \pm 50 \mathrm{kPa}$ pressure, as foreseen under norm UNE-EN-12390-8.

\subsection{Capillary Cuction}

The epoxy paint used to avoid moisture losses described above also prepared the specimens to undergo the capillary suction tests, which were conducted under the standards of norm ASTM C1585-04.

\subsection{Chloride Determination}

This test was based on the NT BUIL 443 method to determine the resistance of hardened concrete to chloride penetration. The specimens used for this test also received epoxy paint visible cavities or crack penetration properties of pairs originated from the An aqueous $\mathrm{NaC}$ which means that initially, the chloride concent

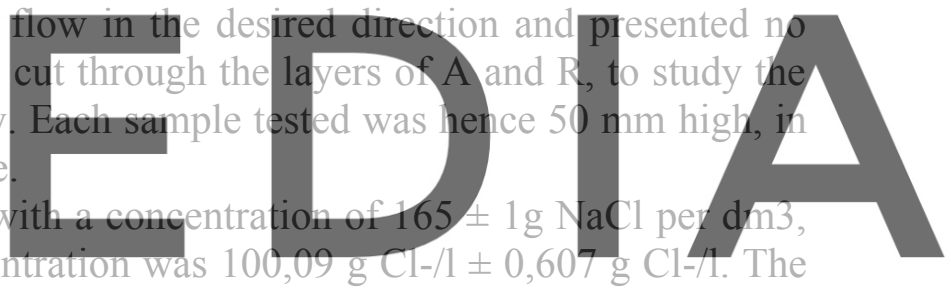
samples were afterward inserted into the $\mathrm{NaCl}$ solution and underwent the following steps:

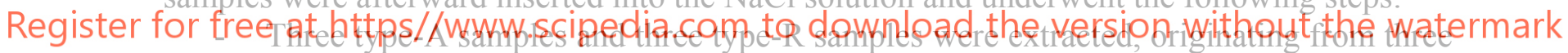
different specimens at 35,60, and 90 days.

- After extracting the samples at 35 days, we replaced the aqueous solution with a new one with identical characteristics to the one used initially.

- Each time the samples were extracted, we conducted proceedings to determine the distance of penetration of the chlorides and the concentration of chlorides at each depth.

The results from the chloride penetration tests are presented as the average of two A samples and two R samples at 35, 60, and 90 days. This test did not consider the metallic test panels from which each sample originated. However, samples A and R came from the same specimen. 


\subsection{Compressive Strength}

The samples were cut and polished at their extremes to obtain a $2-1$ relation on the specimens that would be used to test the compressive strength, meaning that they were twice as high as the diameter of the cylinder. The norm used for this test was UNE 83-302.

\section{Results}

\subsection{Physical Properties}

Concerning the physical properties of the samples, the test shows only slight differences between the dry density and the apparent density. The average values of samples A and R are practically the same (Figure 2).
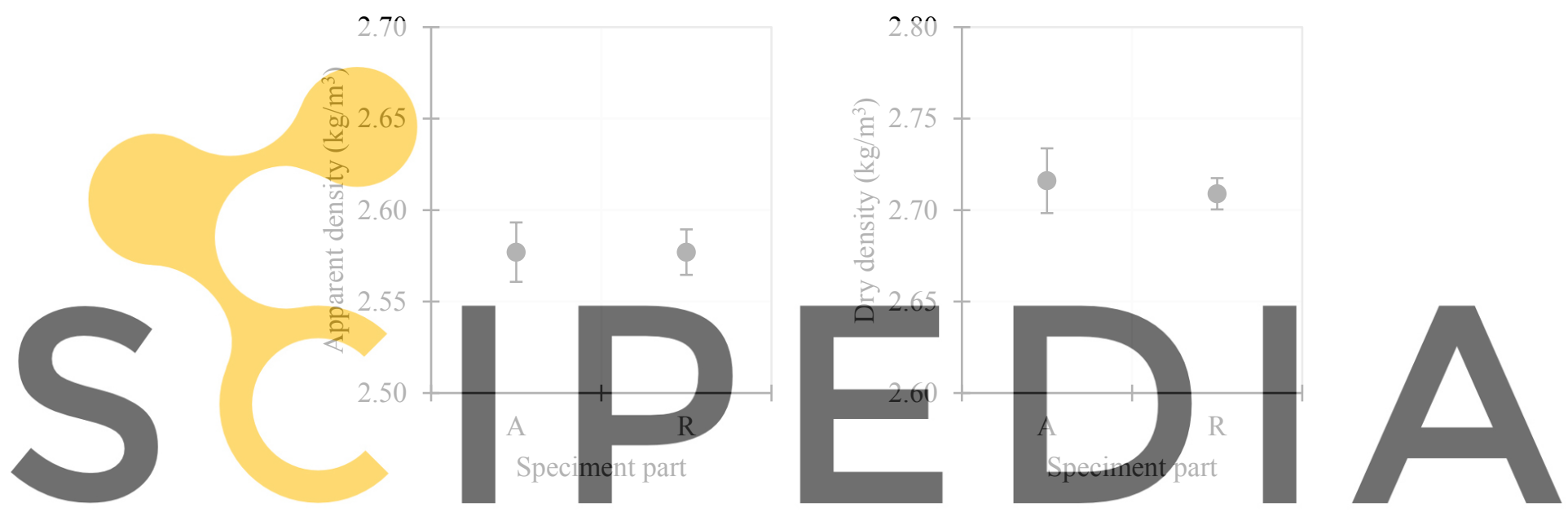

Figure 2. Apparent density and dry density of the samples.

Register for free at https//www.scipedia.com to download the version without the watermark Some differences were observed when it comes to the absorption capacity and porosity of the samples. R-type samples presented more porosity than A-type samples, and in consequence, a larger absorption capacity (Figure 3).

With regards to water penetration under pressure, we observed that there is a significant porous interconnection in both type-A and type-R samples. Throughout the 3-days test, moisture completely penetrated both samples. 

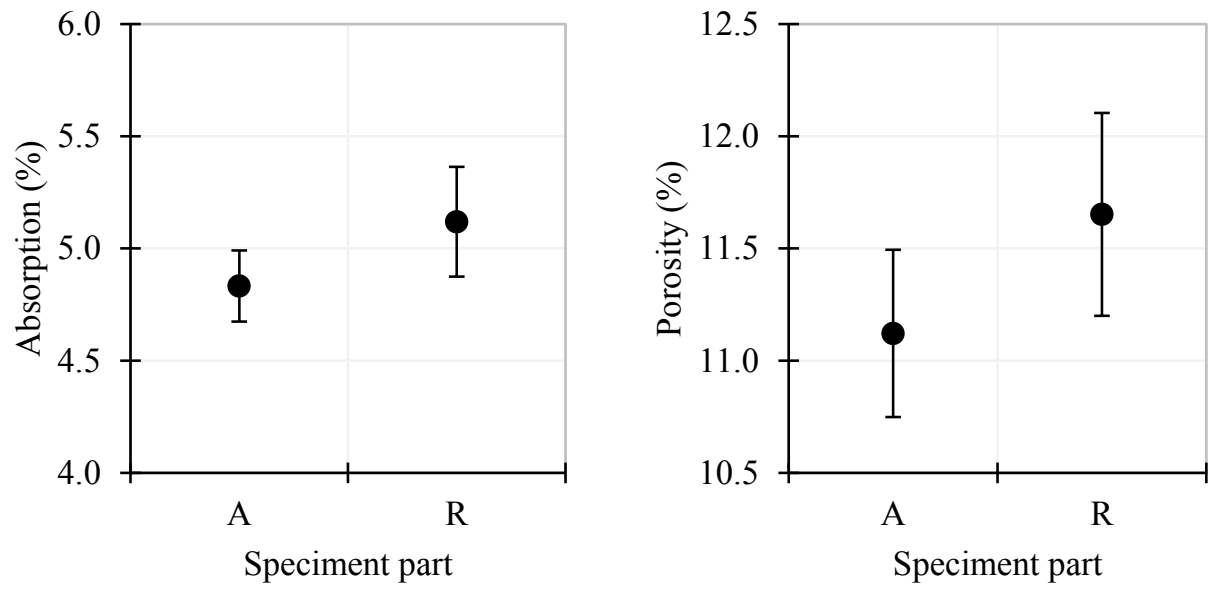

Figure 3. Absorption and porosity of the samples.

The capillary suction test confirmed the porous interconnectivity in both A and R samples, reaching almost a saturation level of $100 \%$ (Figure $4 a$ ). The only significant difference between the type-A and type-R samples performance is that during the first 6 hours of the test, the maximum free absorption was higher on type-A samples (Figure 4b). Forced absorption tests indicated that there were few isolated pores since, when dried, we observed very little water filling those por
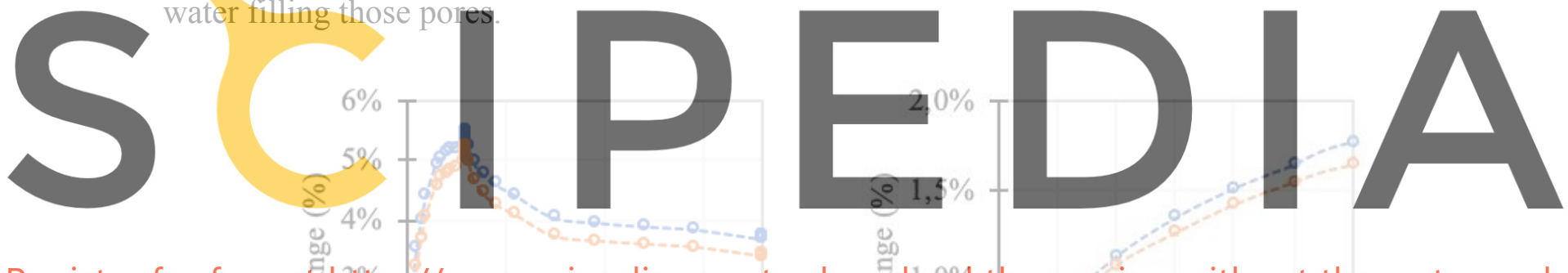

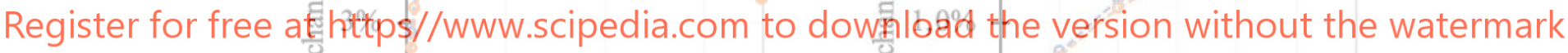
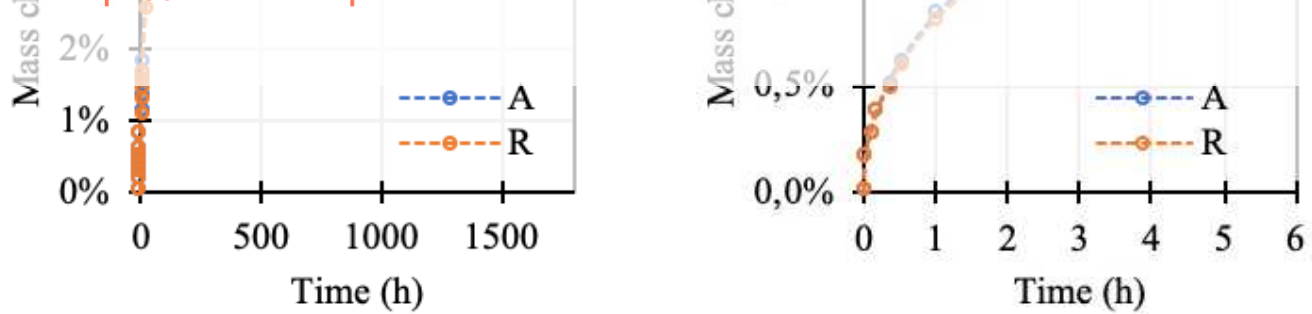

Figure 4. Capillary suction and drying of the samples (a). Capillary suction during the first 6 hours (b).

There is also no significant difference between the loss of water of samples A and R. This confirms that the porosity structure of both samples is very similar, being capable of retaining and losing the same quantity of moisture (Table 2). 
Table 2. Mass of water absorbed during the free and forced absorption test.

\begin{tabular}{cccc}
\hline Speciment part & $\begin{array}{c}\text { Total water } \\
(\mathrm{g})\end{array}$ & $\begin{array}{c}\text { Free } \\
\text { absorption (\%) }\end{array}$ & $\begin{array}{c}\text { Forced } \\
\text { absorption }(\%)\end{array}$ \\
\hline $\mathrm{A}$ & 29.59 & $5.1(94.6 \%)$ & 5.4 \\
\hline $\mathrm{R}$ & 28.36 & $4.8(93.0 \%)$ & 5.2 \\
\hline
\end{tabular}

\subsection{Durability - Chloride Penetration}

The test followed the directions of norm NT BUIL 443 to determine the chloride penetration profiles for samples type-A and type-R at immersion ages 35, 60, and 90 days. Figure 5 shows that there are no significant differences between the profiles determined on both types of samples at their different ages. The test shows that, as the exposure time increases, the concentration of chlorides on the surface increases significantly between 35 and 60 days, but from 60 to 90 days, the increase was not relevant.

It is important to notice that, according to the results of the penetration profiles, the diffusion coefficient decreases as the exposure time increases. Using the square minimums method as dictated by norm NT BUIL 443, the test determined the diffusion coefficients for all cases and showed that the differences are not relevant. (Table 3).

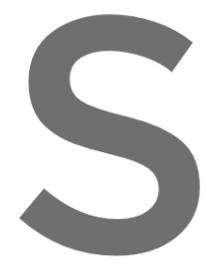

Table 3. Chloride coefficient of the samples at different ages $\left(\times 10^{-11} \mathrm{~m}^{2} / \mathrm{s}\right)$.

\begin{tabular}{|c|c|c|c|}
\hline Specimen part & 35 days & 60 days & 90 days \\
\hline
\end{tabular}

Register for free at https//www.scipedia.com to download the version without the watermark

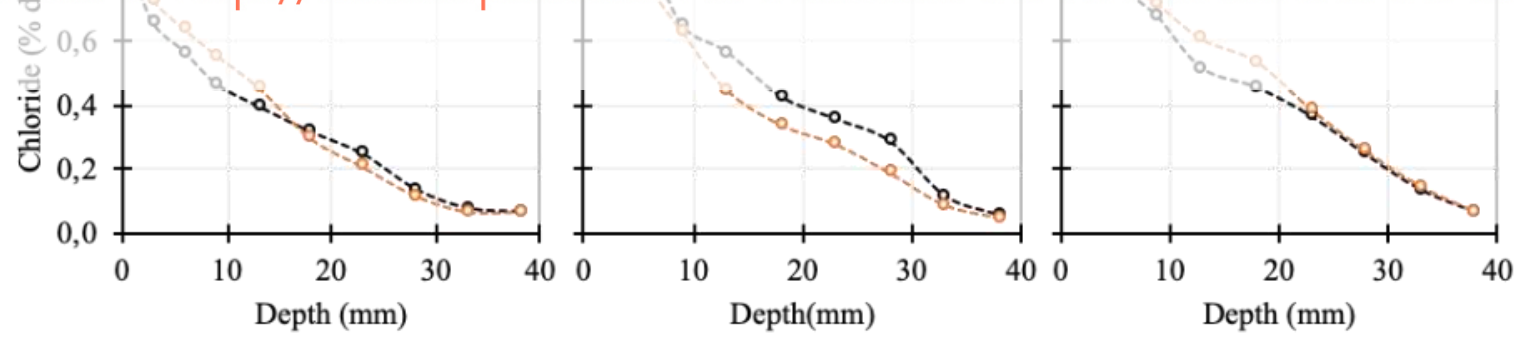

Figure 5. Chloride profiles at 35, 60, and 90 days fo the samples.

This data indicates that an increase of exposure time does not imply a higher accumulation of chlorides at the penetrated depths since, over time, the chloride ions in the solution accumulate at the walls of the sample's pores. The pores hence become progressively saturated, slowing down the aqueous solution's capacity of penetration.

\subsection{Compressive Strength}

For the mechanical tests, samples were obtained from three metallic test panels containing the 
same type of sprayed concrete. Samples originated from the different test panels presented different results despite having used the same sprayed concrete at all of them (Table 4). This can be due to differences in the aggregate distribution during the spraying of the concrete, leading to differences in behavior. In order to verify the distribution of the aggregates in the different samples, a visual analysis was performed. Figure 6 shows that the specimens originated from test panel 2, the one where the aggregate distribution is most homogeneous, presented higher compressive strength.

Table 4. Compressive strength at 28 days of different test panels (MPa).

\begin{tabular}{cccc}
\hline Sample & Test Panel 1 & Test Panel 2 & Test Panel 3 \\
\hline C. S & 41.7 & 51.2 & 44.3 \\
\hline
\end{tabular}

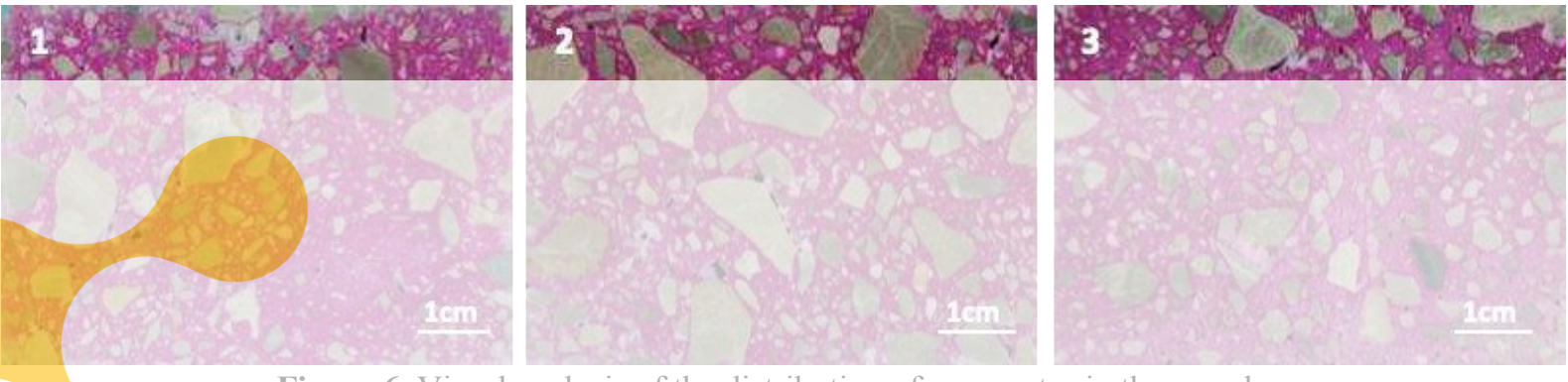

Figure 6. Visual analysis of the distribution of aggregates in the samples.
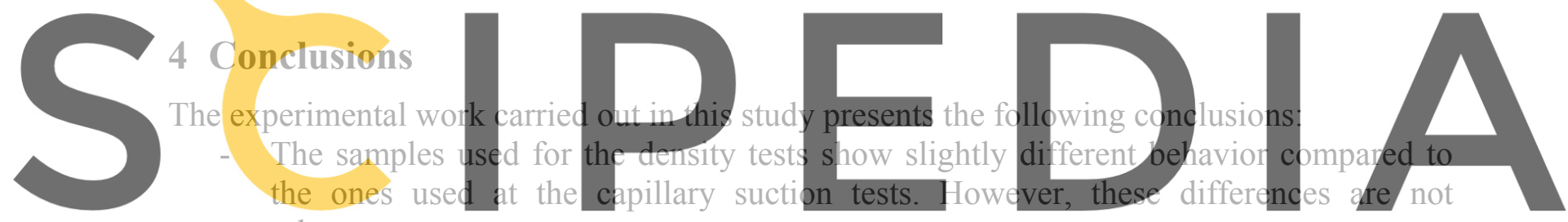
relevant.

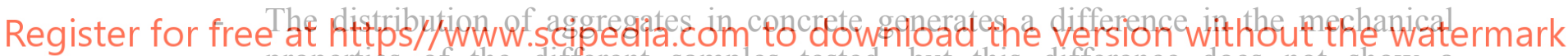
properties of the different samples tested, but this difference does not show a significant impact on the moisture or chloride transport properties.

- On a microstructural level, there are no significant physical differences between shot concrete sample parts A and R. Both parts present a porosity network of similar characteristics.

- The samples of sprayed concrete analyzed in this study presented larger pore interconnectivity compared to regular concrete, which contributed to increase the speed of diffusion of chlorides. This indicates that sprayed concrete could be more vulnerable to chloride penetration than regular concrete.

- There are no noticeable performance differences in terms of chloride penetration between the concrete parts which were exposed to the surface, and the layers exposed to open air. Therefore, there is no proof that the chloride penetration is not homogeneous throughout all the shot concrete layers.

- The high level of concordance of the results obtained from different tests indicates that A and $R$ behave similarly under a chloride attach when completely saturated. 


\section{Acknowledgments}

The authors gratefully acknowledge to the competitive project BIA2016-78740-R: "Materiales proyectados ligeros para refuerzo y la rehabilitación del patrimonio urbano" funded by the Ministry of Economy and Competitiveness, within the 2016 Call for projects "Excelencia y Retos". General Directorate of Scientific and Technical Research. Subdirectorate General for Research Projects.

\section{ORCID}

Diego Fernando Aponte Hernández: http://orcid.org/0000-0001-5737-7819

Marilda Barra Bizinotto: http://orcid.org/0000-0002-1417-1615

Susanna Valls: http://orcid.org/0000-0001-8586-7700

Lucia Fernandez: http//orcid.org/0000-0002-2379-3782

\section{References}

Austin, S. and Goodier, C. (2002). Construction and repair with wet-process sprayed concrete and mortar. Shotcrete magazine, Vol 4.

Galobardes, J. (2013). Characterization and control of wet mix sprayed concrete with accelerators. Ph.D. Thesis, Universitat Politècnica de Catalunya-BarcelonaTECH, Barcelona, Spain.

Galobardes, J.,Cavalaro, S., Aguado, A., Garcia, T., and Rueda, A. (2014). Correlation between the compressive strength and the modulus of elasticity of sprayed concrete. 7th International symposium on sprayed concrete, Modern use of wet mix sprayed concrete for underground support, Norway.

Wang, J., Niu, D., and Zhang, Y(2015). Microstructure and mechanical properties of accelerated sprayed concrete. Materials Structures, Vol. 49, p. 1469-1484.
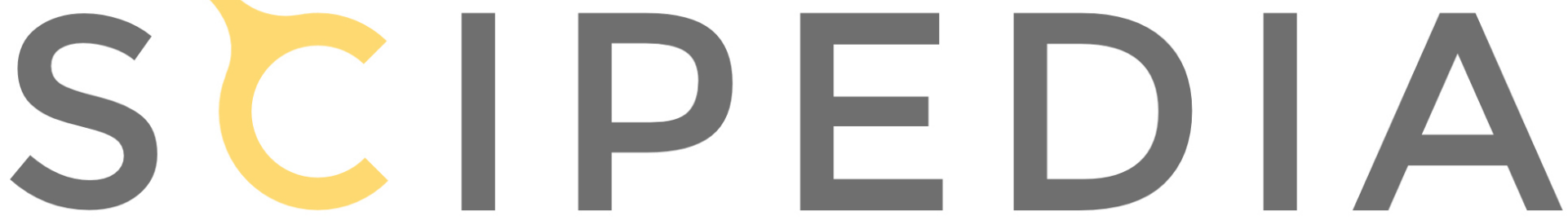

Register for free at https//www.scipedia.com to download the version without the watermark 